\title{
GENEALOGIAS BÁSICAS DAS FAMÍLIAS GOMES MUSSI, CANET E FERRAZ DE CAMPOS
}

\author{
Ricardo Costa de Oliveira ${ }^{1}$
}

- Enviado em 28/05/2016

- Aprovado em 30/05/2016

\section{RESUMO}

O presente trabalho apresenta a genealogia básica das famílias Gomes Mussi, Canet e Ferraz de Campos, todas com importantes conexões empresariais e políticas.

Palavras-chave: Genealogia. Família Gomes Mussi. Família Canet. Família Ferraz de Campos

\section{FAMÍLIA GOMES MUSSI}

1 - William Haj Mussi casado com Glacy Gomes, falecida em 3 de junho de 2013, com 82 anos². Glacy era filha de Edgar Andrade Gomes, prefeito de Irati e de Rosa Fenianos, neta paterna do

\footnotetext{
${ }^{1}$ Professor Associado do Programa de Pós-graduação em Sociologia pela Universidade Federal do Paraná (UFPR). Endereço eletrônico: rco2000@uol.com.br

${ }^{2}$ Disponível em http://www.bandab.com.br/jornalismo/falecimentos-do-dia-4-de-junho/. Acesso 28.maio.2016
} 
Coronel Emílio Baptista Gomes, o primeiro prefeito de Irati $^{3}$, Paraná, em 1907 e proprietário da Madeireira Gomes, a Serraria Irati, uma das maiores madeireiras do Paraná4.

Pais de:

1-1 Roberto Gomes Mussi

1-2 Liliane Mussi. Casada com Carlos Henrique da Silva Ferreira, empresário, diretor da Federação das Indústrias do Estado de São Paulo (Fiesp) e proprietário da Indústria Brasileira de Artigos Refratários e Refratários Brasil. Pais de:

1-2-1 Guilherme Mussi Ferreira, graduado em administração de empresas, Deputado Federal pelo PP de São Paulo, vice-presidente do partido em São Paulo. Guilherme é considerado socialite, já namorou Ana Paula Junqueira e a modelo Carolina Magalhães, neta do senador baiano Antonio Carlos Magalhães (falecido). Foi casado com Luciana Tranchesi. "Na cerimônia mais badalada dos últimos tempos no High Society paulistano, a filha da empresária Eliana Tranchesi, Dona da Daslu, casa-se com Guilherme Mussi em festa chique e animada para 1.300 convidados"5. Posteriormente Guilherme Mussi se casou com Rebeca Abravanel, filha de Sílvio Santos, também se separando alguns meses depois 6 .

1-3 Mariza Mussi Pires

\footnotetext{
${ }^{3}$ ORREDA, José Maria (1974). História de Irati. Irati: Editora Sul do Oeste

${ }^{4}$ BRAGA, Julio Cesar (2011). A vila operária da Madeireira Gomes: trabalho, moradia e dominação - Irati (PR) 1950-1985. IN: Revista Tempo, Espaço e Linguagem (TEL), v. 2 n 2 p. 68-105 mai./ago. 2011 ISSN $2177-$ 6644.Disponível em http://www.revistas2.uepg.br/index.php/tel/article/viewFile/2662/2254. Acesso 28.maio.2016.

${ }^{5}$ Disponível em http://www.terra.com.br/istoegente/edicoes/479/artigo115791-1.htm. Acesso 28.maio.2016.

6 Disponível em http://vejasp.abril.com.br/blogs/terraco-paulistano/2016/05/guilherme-mussi-e-rebeca-abravanel-seseparam/. Acesso 28.maio.2016
} 
1-4 Luis Guilherme Mussi ${ }^{7}$. Presidente do Grupo Rede Mercosul - afiliada Record News no PR Suplente do Roberto Requião no Senado Federal - 2010-2018. Sua carreira profissional foi iniciada no Banco Mercantil do Brasil em 1972. Em seguida trabalhou no Banco Bamerindus do Brasil, onde se retirou para desenvolver atividades nas áreas de comunicação e publicidade;

Presidente do Sindicato das Empresas de Radiodifusão do Paraná em 1979.

Superintendente dos seguintes veículos de comunicação no período de 1977 à 1987:

TV Tibagi - Apucarana / PR.

TV Iguaçu - Curitiba / PR.

TV Naipi - Foz do Iguaçu / PR.

Jornal do Estado do Paraná - Curitiba / PR.

Jornal Tribuna do Paraná - Curitiba / PR.

Constituiu como proprietário as seguintes empresas de comunicação à partir de 1992:

Rádio Exclusiva 95,1 - Curitiba / PR.

TV Exclusiva canal 59 - Curitiba / PR.

Exclusiva Produções - Curitiba / PR.

FM Siriema - Guairá / PR.

Canal 21 - Curitiba/PR.

Convidado pelo Governador Roberto Requião, integrou o corpo dirigente do Estado, como Secretário da Indústria, do Comércio e Assuntos do Mercosul (SEIM), no período de $1^{\circ}$ de janeiro de 2003 à 12 de maio de 2005.

Presidente do Conselho de Política e Desenvolvimento Industrial do Paraná em 2003-2005.

Presidente do Conselho de Administração da Ambiental Paraná Florestas S/A em 2003-2005.

Presidente do Conselho de Administração da Mineropar em 2003-2005.

Presidente do Conselho de Administração da Junta Comercial do Paraná em 2003-2005.

Representante do Governo do Paraná na Agência de Promoção e Exportações do Brasil em 20032005.

Conselho de Administração do Instituto Centro de Comércio Exterior do Paraná - CEXPAR em 2003-2005.

\footnotetext{
${ }^{7}$ Disponível em http://www.luisguilhermegomesmussi.com.br/blog/sobre/. Acesso em 28.maio.2016.
} 
Exerceu também a Presidência do Jockey Club do Paraná em 2004-2006;

Secretário Especial de Governo de 2006 à 2010.

Participou de diversos Conselhos de Administração e de Conselhos Temáticos de Órgãos da estrutura Organizacional do Estado, além de participação no Fórum Nacional dos Secretários de Desenvolvimento, Indústria e Comércio e no Fórum Estadual de Competitividade.

Luis Guilherme Gomes Mussi casou com Yvone Pimentel, filha de Paulo Pimentel e de Yvone Lunardelli. Paulo Pimentel foi Governador do Paraná entre 1966 e 1971. Pais de:

1-4-1 Paula Pimentel Mussi Khury, casada com Alexandre Maranhão Khury, Deputado Estadual, neto de Aníbal Curi.

1-4-2 Guilherme Pimentel Mussi

1-4-3 Luís Fernando Pimentel Mussi

1-5 Vera Lucia Mussi Figueiredo

\section{FAMÍLIA CANET}

1 Jaime Canet. Casado com Anita Lopes. Fazendeiro, comerciante, cafeicultor. Participou de Associações Rurais, Associação Comercial do Paraná e do Clube Curitibano. Faleceu em 15 de junho de $1964^{8}$. Pais de:

\footnotetext{
${ }^{8}$ Diário do Paraná de 16 de junho de 1964, página 3.
} 
1-1 Jaime Canet Junior. Casado com Maria de Lourdes Araújo, filha de Brasílio Araújo e de Zulmira Fonseca, pioneiros e fazendeiros em Bela Vista do Paraíso, Paraná. Jaime Canet Junior. Cafeicultor e pecuarista. Empresário. Rede de Hotéis Deville. Sócio-fundador da empresa Habitação S.A, Incorporadora e Desenvolvimento Imobiliário Canet Jr. Presidente da Café do Paraná, do Banco do Estado do Paraná e vice-governador no período de 1973-1975. Eleito Governador do Paraná, em eleição indireta, pela Assembleia Legislativa a 03 de outubro de 1974, tomou posse a 15 de março do ano seguinte ${ }^{9}$.

1-2 Clélia Canet. Casada com Lauro Ribeiro de Macedo, filho do Capitão Arthur Ribeiro de Macedo, Alto Serventúario da Fiscalização Municipal da capital e de Julia de Oliveira Macedo, filha do Major Jose Luciano de Oliveira e de Angela Lavarde de Oliveira. Com uma filha única Ana Julia Canet de Macedo casado com Luis Spricigo ${ }^{10}$.

1-3 Antonia Canet. Casada com Osmar Stuart.

1-4 Teresa Canet. Casada com Antonio Blitzkow.

1-5 João Canet Neto. Casado com Margot Bettega, filha de Leão Emiro Bettega.

1-6 Maria Helena Canet. Casada com Luiz Renato Mocellin. Filho de Augusto Mocellin e de Dedé Mocellin. Estância Mineral Ouro Fino (Campo Largo). Pais de:

1-6-1 Cristiane Canet Mocelin. Foi casada com Ricardo do Rego Almeida. 1-6-2 Augusto Mocellin Neto.

\footnotetext{
${ }^{9}$ Disponível em http://www.casacivil.pr.gov.br/modules/conteudo/conteudo.php?conteudo=81. Acesso 28.maio.2016

${ }^{10}$ Disponível em http://pagfam.geneall.net/3935/pessoas.php?id=1082268. Acesso em 28.maio.2016
} 


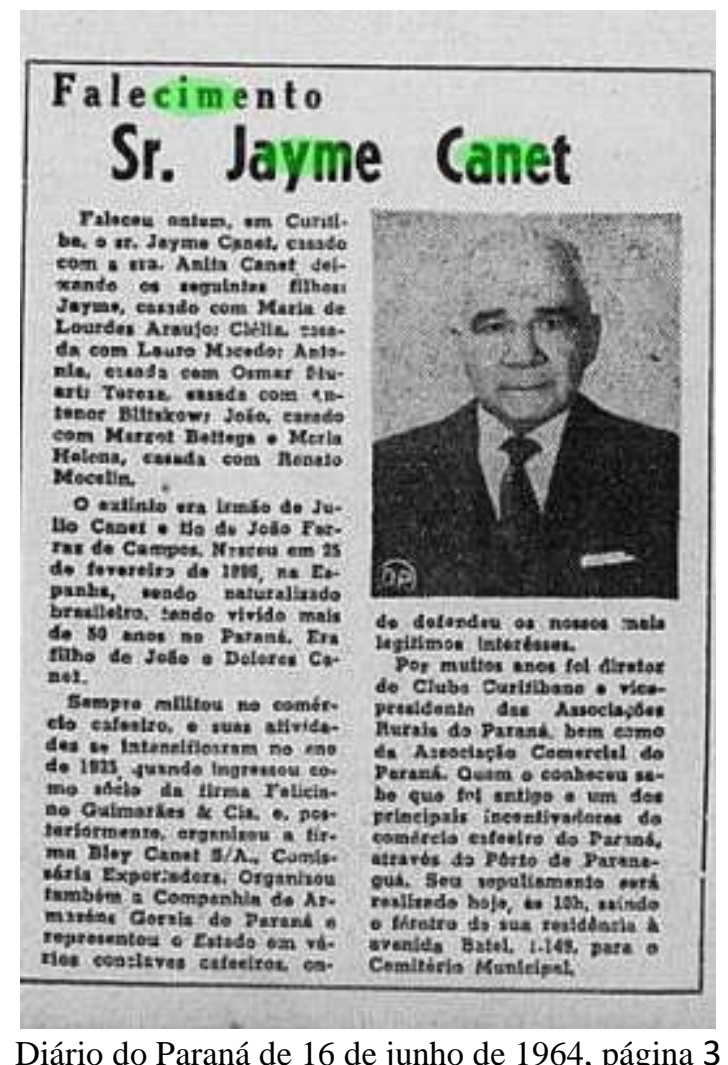

\section{FAMÍLIA FERRAZ DE CAMPOS}

Jaime Canet era tio de João Ferraz de Campos, logo primo do Governador Jaime Canet Junior.

João Elísio Ferraz de Campos. Nasceu em 23 de dezembro de 1942, na cidade de Paranaguá. Filho de João Ferraz de Campos e de Edy Ferraz de Campos; João Elísio casou com maria Christina Leão de Macedo, tem duas filhas: Ana Carolina e Ana Paula. Bacharelou-se em Direito pela Universidade Católica do Paraná. Cargos e funções Superintendente da Fundação Educacional do Paraná em 1973 - 1975. Secretário de Estado da Administração em 1975 -1978. Deputado Estadual no período de 1979 a 1982. Representou o Paraná no CODESUL e CONFAZ. Foi ViceGovernador, tendo acumulado o cargo de Presidente do Banco de Desenvolvimento do Paraná S.A. - BADEP, até maio de 1984, quando assumiu as funções de Secretário de Estado das Finanças. 
Membro do CEDES - DER - FUNDEPAR. Exerceu diversas funções na EMOPAR, CELEPAR, CEAG, ABDE, COHAPAR, CENDI, METRONOR, BAMERINDUS, COSEPA. Governador do Paraná em 09 de maio de 1986 à 15 de março de $1987^{11}$. Presidente da Fenaseg - Federação Nacional das Seguradoras.

Edy Pereira Ferraz de Campos ${ }^{12}$. Faleceu ontem (12/07/2010), aos 90 anos de idade, a Sra. Edy Pereira Ferraz de Campos, de tradicional família paranaense. Edi era filha de Elísio Pereira Alves e de Leonor Pereira de Camargo Alves ${ }^{13}$ (Genealogia Paranaense III, 67). Viúva de João Ferraz de Campos, ex-presidente do Centro de Comércio de Café de Paranaguá, deixa três filhos: Maria Leonor, Paulo Roberto e João Elísio, este ex-governador do Paraná. João, advogado, foi vereador em Paranaguá, em $1956^{14}$, eleito pela legenda do Partido Social Democrático, Superintendente do Porto de Paranaguá. Trabalho na firma Brasílio de Araújo.

Paulo Roberto Ferraz de Campos - Filho de João Ferraz de Campos e de Edi Pereira. Casado em 1965 com Maria Helena Bettega, filha de Lídio Paulo Bettega, industrial, presidente da FIEP Federação das Indústrias do Estado do Paraná e de Semiranis Macedo Seiler (Genealogia Paranaense, II, 312).

Maria Leonor - Filha de João Ferraz de Campos e de Edy Pereira. Casada com Pedro dalla Riva

O sogro de João Elísio Ferraz de Campos era “Agílio Leão de Macedo, nasceu em Curitiba-Pr no dia 11 de Março de 1921 e faleceu no Rio de Janeiro no dia 28 de Agosto de 1983. Filho de Tobias

11 Disponível em http://www.casacivil.pr.gov.br/modules/conteudo/conteudo.php?conteudo=86. Acesso em 28.maio.2016.

12 Disponível em http://www.gazetadopovo.com.br/servicos/falecimentos/lista-de-falecimentos3qeq7whuw324gnyggysvnwu32. Acesso em 28.maio.2016.

${ }^{13}$ Correio do Paraná. 28/12/1938.

14 
de Macedo e Maria Clara Leão de Macedo. Casado com Rosy Woiski Leão de Macedo, seus filhos: Maria Christina Macedo Ferraz de Campos, casada com João Elísio Ferraz de Campos e Agilio Leão de Macedo Filho casado com Lucia Frein de Macedo. Formado em Engenharia Química pela Universidade Federal do Paraná em 1943. Foi Fundador e Presidente da Sociedade Hípica Paranaense, Fundador do Iate Clube de Caiobá, Membro do Conselho Deliberativo de Arbitramento do DETRAN, Membro do Conselho Municipal de Transporte Coletivo, Diretor Presidente da Indústria Orestes Codega Ltda, Diretor da Leão Junior S/A"15.

\section{BASIC GENEALOGIES ABOUT FAMILIES GOMES MUSSI, CANET AND FERRAZ DE CAMPOS}

\section{ABSTRACT}

This paper presents the basic genealogy of families Gomes Mussi, Canet and Ferraz de Campos, all with important business and political connections.

Key-words: Genealogie. Family Gomes Mussi. Family Canet. Family Ferraz de Campos

\footnotetext{
${ }^{15}$ Disponível em http://culturadematinhos.blogspot.com.br/2012/07/nomes-de-rua-quem-foi-agilio-leao-de.html Escrito por Agilio Leão de Macedo Filho. Acesso em 28.maio.2016.
} 